\title{
BMJ Open Effects of dental general anaesthesia treatment on early childhood caries: a prospective cohort study in China
}

\author{
Haofeng Jiang, Lu Shen, Dan Qin, Songlin He, Jinhua Wang
}

To cite: Jiang $H$, Shen $L$, Qin D, et al. Effects of dental general anaesthesia treatment on early childhood caries: a prospective cohort study in China. BMJ Open 2019;9:e028931. doi:10.1136/ bmjopen-2019-028931

- Prepublication history for this paper is available online. To view these files, please visit the journal online ()

$\mathrm{HJ}$ and $\mathrm{LS}$ are joint first authors.

Received 03 January 2019 Revised 17 August 2019 Accepted 20 August 2019

A) Check for updates

(c) Author(s) (or their employer(s)) 2019. Re-use permitted under CC BY-NC. No commercial re-use. See rights and permissions. Published by BMJ.

Department of Pediatric Dentistry, College of Stomatology, Chongqing Medical University; Chongqing Key Laboratory of Oral Diseases and Biomedical Sciences; Chongqing Municipal Key Laboratory of Oral Biomedical Engineering of Higher Education, Chongqing, China

Correspondence to Dr Songlin $\mathrm{He}$; songlinhe@cqmu.edu.cn

Professor Jinhua Wang; 500190@hospital.cqmu.edu.cn

\section{ABSTRACT}

Objectives To evaluate the success rates of dental procedures, the recurrence rates of caries and changes in oral health-related quality of life $(\mathrm{OHRQ} \mathrm{L})$ in children following treatment for early childhood caries (ECC) under dental general anaesthesia (DGA) in Chongqing, China. Design A single-centre prospective cohort study conducted from December 2016 to June 2017.

Setting A tertiary stomatological hospital in Chongqing, China.

Participants A total of 159 children aged 2-5 years who received treatment for ECC under DGA were included. Main outcome measures The primary outcomes were the success rates of dental procedures (the number of successful procedures divided by the total number of procedures) and the recurrence rates of caries. The success and recurrence rates were evaluated by a specialised examiner. The secondary outcome was the change in children's OHRQoL after DGA treatment, which was measured with the Early Childhood Oral Health Impact Scale (ECOHIS).

Results Overall, 117 children (73.6\%) and 101 children (63.5\%) participated in 6-month and 12-month clinical examinations, respectively, and 151 children (95.0\%) completed OHRQoL surveys pretreatment and at 1, 3, 6 and 12 months post-treatment. The resin composite, stainless steel crown, indirect pulp capping, pulpectomy, space maintenance and dental sealant success rates were $89.6 \%, 96.3 \%, 96.0 \%, 94.4 \%, 76.9 \%$ and $92.9 \%$, respectively, at 6 months and $78.8 \%, 95.1 \%, 92.2 \%$, $88.9 \%, 63.6 \%$ and $89.3 \%$, respectively, at 12 months. 10 (8.5\%) and 19 children (18.8\%) developed recurrent caries within 6 and 12 months, respectively. Within 1 year of treatment, the total ECOHIS scores at each post-treatment time point were still significantly lower than those at pretreatment, although they had increased slowly over time.

Conclusions Overall, high success rates were obtained for the dental procedures, and the children's OHRQoL significantly improved after treatment. However, there was a tendency towards caries relapse, and the children's OHRQoL deteriorated over time.

\section{INTRODUCTION}

In children 71 months of age or younger, the presence of one or more decayed, missing or filled surface on any of the primary teeth is defined as early childhood caries (ECG). ${ }^{1}$ In

\section{Strengths and limitations of this study}

- A prospective design was used to study clinical outcomes over time, changes in oral health-related quality of life (OHRQoL) scores and caries recurrence.

- The validated Early Childhood Oral Health Impact Scale was used to measure $\mathrm{OHRQ} \mathrm{L}$ in children.

- A large proportion of children did not participate in the clinical examination after treatment, which may lead to bias in some outcome indicators.

- The clinical examinations may be inaccurate because a few data points were from unscheduled recalls conducted by uncalibrated examiners, and some children did not cooperate during the examinations.

- A lack of routine rubber dam use is a significant limitation of this study as it is critical for restorative success.

low/middle-income countries, ECC remains an important public health problem. ${ }^{2}$ National data indicate that, among 5 -year-old children in China, the prevalence of caries in primary teeth is $70.9 \% .^{3}$

Most children with ECC receive systematic treatment with regular behavioural management in a conventional office environment, but a small number require an advanced approach, such as dental general anaesthesia (DGA) treatment in the operating room, due to their limited ability to cooperate during extensive and complex treatment procedures. ${ }^{1}$ GA can provide a better operative environment in which high-quality dental treatment can be completed in a single session. $^{24}$

Under GA, dentists can provide a variety of treatment procedures for children. ${ }^{5}$ Previous studies ${ }^{46}$ have shown that restorative treatment for children with severe dental caries often fails. This may be due to severe structural damage and enamel demineralisation of abutment teeth, rendering restorations more prone to marginal defects. Among restorative procedures, the durability of stainless steel 
crowns (SSCs) is higher, and the risk of retreatment for interproximal caries restored with SSCs is lower. ${ }^{4}$

Although children receive active treatment under GA, they may have caries recurrence after a few months. A study $^{7}$ of 269 children treated similarly showed that 167 had at least one recall appointment within 12 months, and $24 \%$ of these children developed new caries. Of the 36 patients who attended recall appointments at 13-24 months, 53\% developed new caries. A recent study ${ }^{8}$ reviewed 278 children treated under GA, revealing that $22 \%$ had a caries recurrence during the 3-year follow-up period.

When evaluating the effect of dental treatment, both clinical changes and the impact of treatment on the quality of life of the patient should be measured. ${ }^{9}$ Oral health-related quality of life (OHRQoL) is a phenomenon used in measuring the impact of oral disease on the general condition and daily life of patients. ${ }^{10}$ A recent systematic review $^{11}$ indicated that children's OHRQoL was significantly improved after DGA treatment. However, most of the follow-up periods in these studies were shorter than 3 months.

In the literature, no study has examined the clinical outcomes following treatment for ECC performed under GA in Southwest China, because the DGA technology is relatively new in this region. Local paediatric dentists depend on international studies to provide information on the efficacy of dental treatment under GA. The difference in population characteristics and DGA treatment processes elsewhere may mean different the dental procedure success rates and caries recurrence rates. Accordingly, the primary purpose of this study was to evaluate the success rates of dental procedures involving different tooth types and restorative materials and evaluate the recurrence rates of caries and the factors that influence it following DGA treatment for ECC during a 1-year follow-up period in Chongqing, Southwest China. Meanwhile, considering that the sustainability of the observed OHRQoL improvements after DGA treatment is not currently clear, ${ }^{12}$ the secondary purpose of this study was to evaluate OHRQoL changes in patients during the year following treatment.

\section{MATERIALS AND METHODS \\ Study sample}

This was a prospective cohort study with a 1-year follow-up period. The study population was a consecutive convenience sample consisting of 159 out of 249 preschool children who received treatment for ECC under GA at the Stomatological Hospital of Chongqing Medical University from December 2016 to June 2017. The following inclusion criteria were applied: (1) children aged between 2 and 5 years old and (2) children classified as American Society of Anesthesiologists class I. However, the following cases were excluded: (1) children with developmental disorders or general diseases, such as cerebral palsy, heart failure or Down syndrome; (2) children treated under GA for other conditions, such as retained deciduous teeth, short labia, tongue tie or supernumerary teeth and (3) children whose parents had no mobile phone access or were not able to communicate fluently. Participation in the study was voluntary. The parents of each child were informed about the survey.

\section{Data collection}

The study consisted of clinical examinations performed before treatment and at 6-month and 12-month recall examinations. OHRQoL surveys were also completed pretreatment and at 1, 3, 6 and 12 months post-treatment. The data collected in this study included demographic information, baseline caries experience (baseline decayed, missing and filled teeth (dmft) index/decayed, missing and filled surface ( $\mathrm{dmfs})$ index), dental treatment information, the success rates of dental procedures, the recurrence rates of caries and children's OHRQoL.

Demographic information: Demographic information was collected via preoperative questionnaires on the day before the operation and included the following indicators: the child's name, gender and age; the relationship between the parents and the child (mother, father or grandmother/grandfather); family monthly income ( $\leq ¥ 10000$ or $>¥ 10000$ ); area of residence (city/town or village) and contact information.

Baseline caries experience: On the day before the operation, the same examiner checked the dental condition of the children according to WHO standards. ${ }^{13}$ The examiner was blinded to who performed the treatment in the operation room. A dental mirror and community periodontal index (CPI) probe were used for the examination under an artificial light source. The caries status was determined with the $\mathrm{dmft}$ and $\mathrm{dmfs}$ indexes.

Before the examinations, the examiner was calibrated by this study's principal investigator. High intraexaminer reliability was evaluated via examinations in which 13 children received treatment for ECG under GA twice with a 2-week gap between the examinations (overall kappa $>0.8$.

Dental treatment information: On the day after treatment, information on the dental treatment, including treatment provider, type, quantity and tooth position, was collected from hospital records.

In this study, all children were treated by the same five dentists, who had at least 10 years of paediatric experience. Dentists had the same treatment approach to ECC management. The caries were restored by resin composites, including direct filling of various cavity types and anterior composite crowns. Teeth with deep carious lesions without pulp exposure received indirect pulp treatment (IPC). Teeth with pulpal involvement underwent pulpectomy and were restored by resin composites or SSCs. Teeth with a clear perforation in the pulp chamber bottom, furcation involvement or root resorption were extracted. The space between the extracted posterior primary teeth was maintained. If the parents agreed, dental sealants and/or full-mouth fluoride 
(Duraphat, Colgate-Palmolive (China), Guangzhou, China, active ingredient was $5 \%$ sodium fluoride) were administered. A rubber dam was not used in all cases due to cost constraints.

Success rates of dental procedures: At 6 and 12 months post-treatment, participants were contacted by telephone, and a clinical examination was arranged to evaluate the success rates of the dental procedures. At the same time, necessary dental treatments were performed, topical fluoride was applied, and brushing instructions and dietary counselling were emphasised. All examinations were completed by the same examiner who performed a baseline caries examination with a dental mirror and a probe while the patient sat in a dental chair. When necessary, a radiographic examination (when feasible) was performed. Similar to the baseline examination, the examiner was blinded to the provider who performed the treatment in the operating room. If one or more of the following situations was encountered, the treatment procedure was considered a failure. ${ }^{1415}$

1. Restorative procedures (resin composite and SSC): (1) missing, fractured, cracked or poorly adapted restorations; (2) open margins, perforated or missing SSCs/anterior composite crowns; (3) secondary caries and (4) in teeth restored via only restorative procedures and without pulp therapy, the restorative procedures were considered a failure if any symptoms used to determine the failure of pulp therapy were found.

2. Pulp therapy (IPC and pulpectomy): (1) sensitivity to percussion; (2) localised pain; (3) the presence of swelling or an abscess and (4) radiographic evidence of interradicular or furcation pathology.

3. Space maintenance: missing or fractured space maintainer.

4. Dental sealants: (1) incomplete coverage with open margins; (2) secondary caries and (3) complete loss of fissure sealant.

In addition to the scheduled follow-up visits, patients may also have participated in one or more unscheduled visits within 12 months due to emergent symptoms or other special circumstances. Related data were collected from electronic (revisited in our hospital) or paper records (revisited in another hospital). The findings obtained in these appointments were included in the final evaluation.

Recurrence rates of caries: A new lesion found on previously untreated teeth or on a tooth surface was defined as recurrent caries. ${ }^{1}$ Caries found on the edge of existing restorations were regarded as secondary caries (included in procedure failures). ${ }^{1}$ The methods used to assess the recurrence rates of caries were the same as those used to assess the baseline $\mathrm{dmft} / \mathrm{dmfs}$ and the success rates of dental procedures. If the $\mathrm{dmfs}$ at follow-up was higher than that at baseline, the child was recorded as having a caries recurrence. The caries recurrence rate was equal to the number of children who had a caries recurrence divided by the total number of children examined.
Children's OHRQoL: To measure children's OHRQoL, we used a previously certified Chinese version of the Early Childhood Oral Health Impact Scale (ECOHIS) ${ }^{16} 17$ that was developed by Pahel $e$ al. ${ }^{18}$ The ECOHIS consisted of 13 items and comprises 2 main subscales. Items 1-9 constituted the child impact section (CIS), which covered the following four domains: child symptoms (item 1), child function (items 2-5), child psychology (items 6-7) and child self-image and social interactions (items 8-9). Items 10-13 constituted the family impact section (FIS), which covered the following two domains: parental stress (items 10-11) and family functioning (items 12-13). Each of the items in the CIS and FIS was given a score ranging from 0 to 4 according to the frequency of oral health-related problems: never (score 0 ), hardly ever (score 1), occasionally (score 2), often (score 3) and very often (score 4). Importantly, a 'Don't know' response was also offered because the respondent was not always the person whose OHRQoL was being assessed; this avoided a proxy overestimation of treatment effects. The children's OHRQoL was assessed in a pretreatment questionnaire and in telephone interviews performed at 1, 3, 6 and 12 months post-treatment. All interviews were completed by the same trained investigator. Only parents who consented to participate and completed a pretreatment questionnaire were surveyed over the telephone.

\section{Statistical analysis}

All data were collected and analysed with SPSS software (V.20.0, SPSS). The participants' data were excluded from the study if their key demographic data, such as child's name and contact information, were missing, as we would not have been able to identify them and conduct a follow-up without this information. In addition, the participants' data were excluded from the OHRQoL surveys if any one of their ECOHISs contained more than $30 \%$ missing items (scored 'Don't know' or left blank). ${ }^{19-21}$ For scales with a missing item rate of less than $30 \%$, the missing values were replaced by the average score from the sample for that item. ${ }^{19-21}$

Frequencies/percentages and means/SDs are shown to describe categorical and continuous variables, respectively. The total scores for ECOHIS, CIS, FIS and each domain were calculated to measure the children's OHRQoL. Changes in scores were computed by subtracting the post-treatment scores from the pretreatment scores and used to represent improvement or deterioration in OHRQoL. We used effect size (ES) to indicate the meaningful magnitude of the change. The ES statistics were calculated by dividing the mean score changes by the SD of the pretreatment scores. An ES $<0.2$ indicated a small change, $\mathrm{ES}=0.2-0.7$ indicated a moderate change and ES $>0.7$ indicated a large change.

We used the $\mathrm{X}^{2}$ test or Fisher's exact test to identify differences among categorical variables. Because the continuous variables were not normally distributed (Shapiro-Wilk's test, $\mathrm{p}<0.05$ ), non-parametric tests, including the Wilcoxon rank test and Friedman test, were 


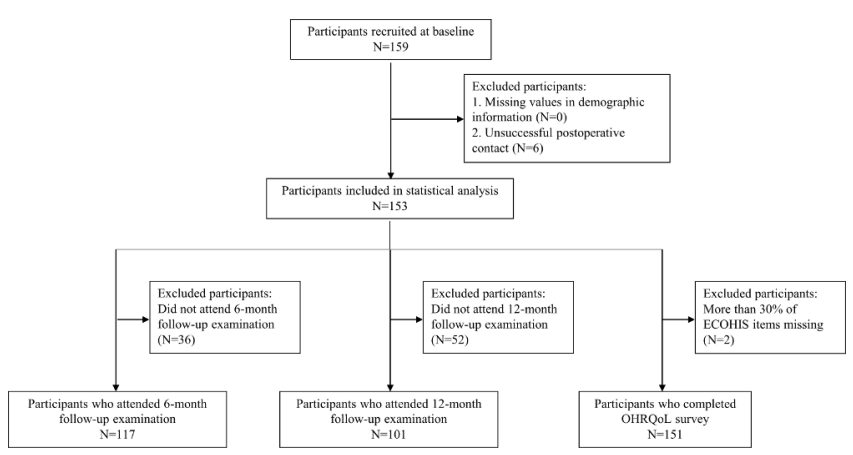

Figure 1 Participant selection. ECOHIS, Early Childhood Oral Health Impact Scale; OHRQoL, oral health-related quality of life.

used to identify differences among continuous variables. A $p<0.05$ was considered significant for all comparisons.

\section{Patient and public involvement}

No patients were involved in the development of the research question and outcome measures, nor were they involved in the design, the recruitment or the conduct of the study.

\section{RESULTS}

\section{General characteristics}

Figure 1 shows the participant selection process. In all, 159 children were recruited at baseline. Six children were excluded because they were not successfully contacted during the postoperative follow-up period. Therefore, the final study sample included 153 children. Among them, 117 children $(73.6 \%)$ and 101 children $(63.5 \%)$ participated in clinical examinations at 6 and 12 months post-treatment, respectively, and 151 children (95.0\%) completed OHRQoL surveys pretreatment and at 1, 3, 6 and 12 months post-treatment.

The baseline characteristics of the participants are shown in table 1 . There were no significant differences in the baseline characteristics between those who were lost to follow-up and those who were followed up with.

\section{Success rates of dental procedures}

Table 2 presents success rates of dental procedures at the 6-month and 12-month examinations. Fifty-nine children $(50.4 \%)$ and 38 children $(37.6 \%)$ did not have failed procedures (ie, all procedures were successful), respectively. The resin composite, IPC and pulpectomy success rates were significantly lower at 12 months than at 6 months $(\mathrm{p}<0.01)$. There was no significant difference in the success rates of dental procedures between dentists ( $>0.05)$.

The success rates of restorative procedures and pulp therapy were compared between different restorative materials and tooth types. The 6-month and 12-month success rates were significantly lower for anterior resin composites than for posterior resin composites. There was no significant difference in the 6-month success rates between posterior resin composites and SSCs, but the success rate was higher for the latter than the former at 12 months. The 6-month success rate of posterior IPCs was not significantly different from that of anterior IPCs, but the 12-month success rate was significantly higher for posterior IPCs. There was no significant difference in the success rates of pulpectomy performed on anterior and posterior teeth regardless of if they were evaluated at 6 or 12 months post-treatment.

\section{Recurrence rates of caries}

Table 3 shows data on the caries recurrences. At the 6-month and 12-month clinical examinations, the $\mathrm{dmft}$ scores were $10.0 \pm 4.7$ and $10.9 \pm 4.9$, respectively, and the dmfs scores were $35.9 \pm 18.6$ and $38.4 \pm 18.1$, respectively, which were significantly higher than those at baseline $(\mathrm{p}<0.05)$. Overall, 10 children $(8.5 \%)$ and 19 children (18.8\%) developed recurrent caries within 6 and 12 months after treatment, respectively. The recurrence rates were significantly higher at 12 months than at 6 months $(\mathrm{p}=0.03)$. At 12 months post-treatment, relapse was significantly associated with family monthly income, family residence, baseline dmft scores, baseline dmfs scores and participation in the 6-month follow-up examination $(\mathrm{p}<0.05)$. However, there was no association between relapse and any factor at 6 months $(p>0.05)$.

\section{Children's OHRQOL}

Table 4 shows the ECOHIS, CIS, FIS and domain scores. Within 1 year after treatment, the ECOHIS, CIS and FIS scores were significantly lower at each postoperative time point than those before treatment, but they increased slowly over time. Compared with the preoperative scores, the total ECOHIS scores decreased significantly by $75.4 \%$ at 1 -month post-treatment, by $67.5 \%$ at 3 months post-treatment, by $58.9 \%$ at 6 months post-treatment and by $42.1 \%$ at 12 months post-treatment. In all domains, the largest reduction was in 'child symptoms', and the smallest was in 'child self-image and social interactions'.

Figures 2 and 3 present changes in the ECOHIS scores in the successful/unsuccessful groups at the 6-month and 12-month follow-up examinations, respectively. The postoperative ECOHIS scores increased faster in the children who experienced a procedure failure (Unsuccessful group) than in those who did not (Successful group). Figures 4 and 5 present changes in the ECOHIS scores in the recurrence/non-recurrence groups at the 6-month and 12-month follow-up examinations, respectively. Similar increases were observed in children who developed new caries (recurrence group) and in children who did not (non-recurrence group).

\section{DISCUSSION}

In this study, ECC treatment performed under GA was evaluated over a 1-year follow-up period to explore the following three issues: the quality of dental procedures, caries recurrence and effects on children's OHRQoL. Most of the procedures were successful, and the children's 


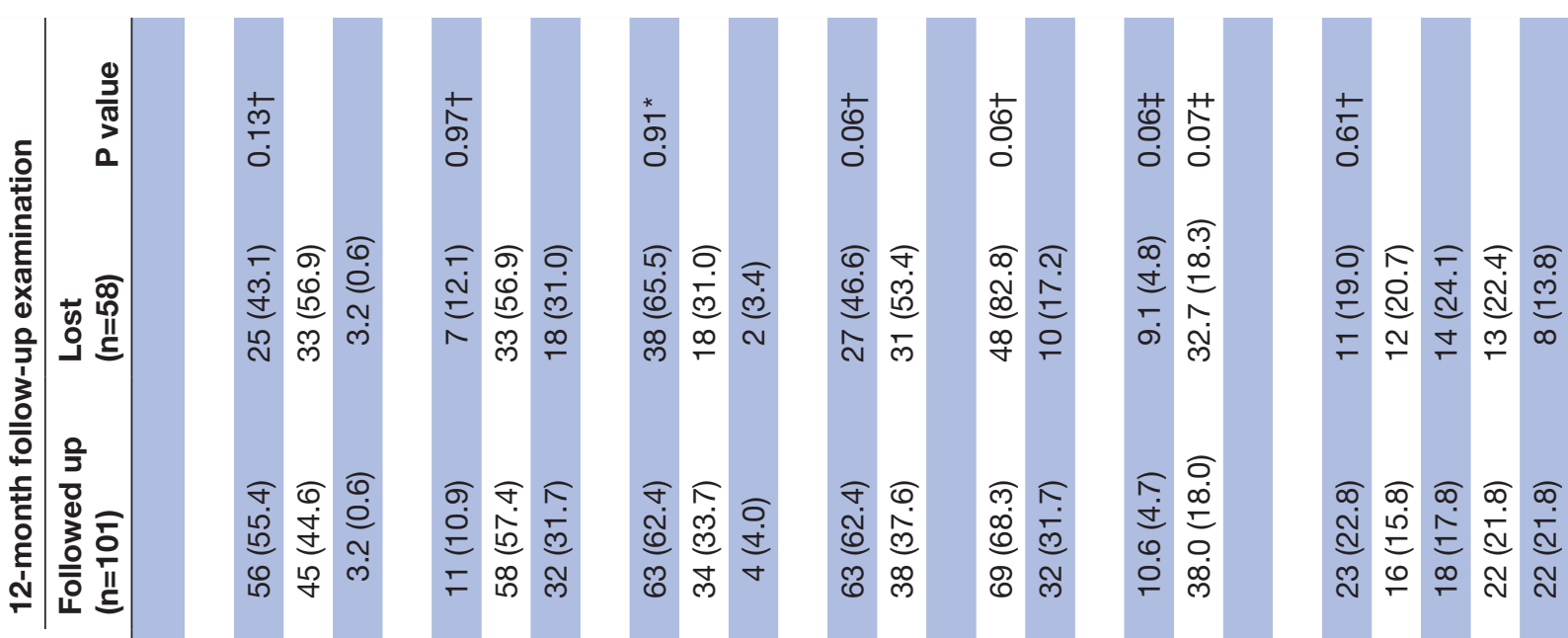

守

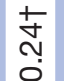

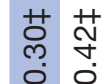

$\underset{0}{+}$

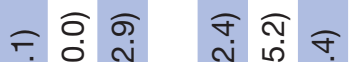

क ลิ

过 过

ㄷำ

ल 으

드 $\stackrel{\infty}{\leftarrow}$

ก 으 -

ต

กิ

ก ल

กิ 官

농

ब्र ल्ల

$\stackrel{\infty}{\square}$

है

우

ธิ क ल ส

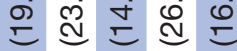

$\infty$ 으 0 ㅈ

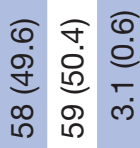

ก 0

m롤

드

बै ब्र

$\bullet$ ஓ ल

이 है

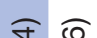

ค

(].

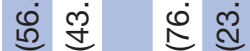

起

8 in

$\infty \stackrel{\infty}{\sim}$

वे

สิจ สิธ

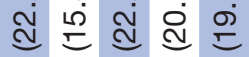

인 $\stackrel{\sim}{\sim}$

$\stackrel{*}{\stackrel{*}{n}}$

…

ํํㅇ

ํㅜㅇ

贲

$\stackrel{*}{\stackrel{*}{\circ}}$

○ิ ชิ

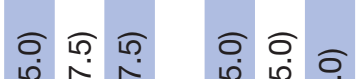

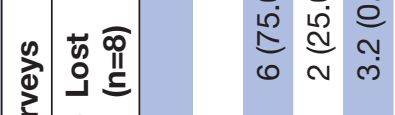

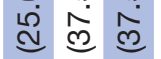

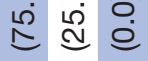

เก็น

ฮิ

oิ

๙ิ

เ $m$

100

ำ

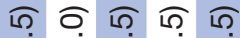

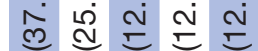

m $\sim r-$

क 은

लฺ

造 急

N

के हु 0

당ㅇㅁ

过

$\ddot{\omega}: \stackrel{0}{\circ}$

ธุ สุ ธก ธก สุ

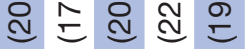

ल थे एँ

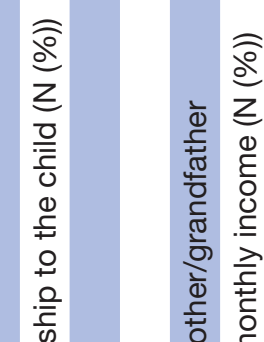

$\frac{\widehat{a}}{2}$

응

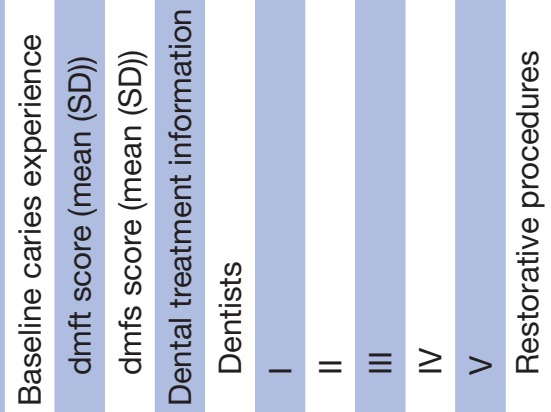




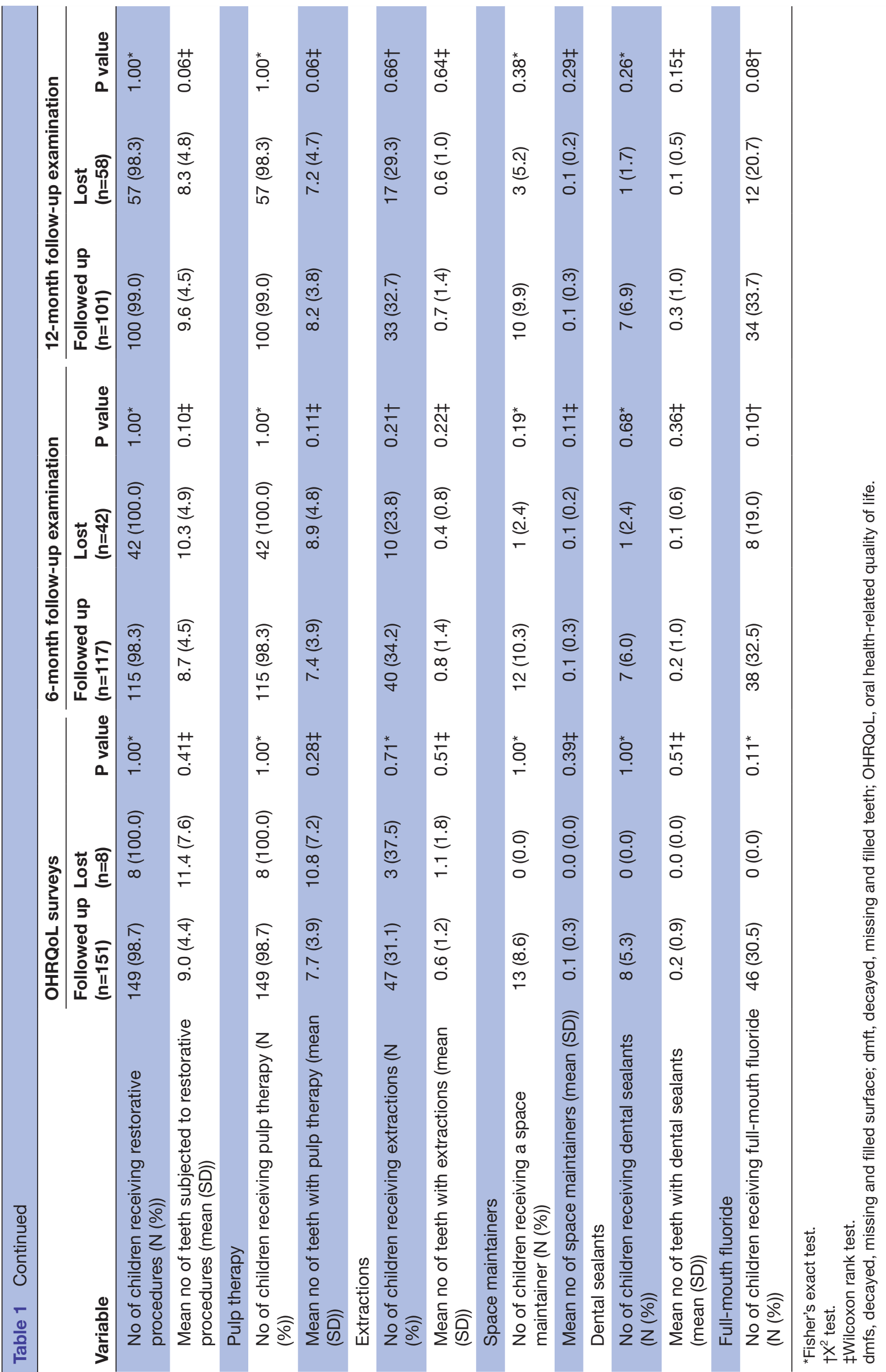


Table 2 Success rates for restorative procedures, pulp therapy and other procedures at the 6-month and 12-month follow-up examinations

\begin{tabular}{|c|c|c|c|c|c|c|}
\hline \multirow[b]{2}{*}{ Procedures } & \multicolumn{3}{|c|}{ 6-month follow-up examination ( $n=117$ ) } & \multicolumn{3}{|c|}{ 12-month follow-up examination $(n=101)$} \\
\hline & $\begin{array}{l}\text { Total no of } \\
\text { procedures }\end{array}$ & $\begin{array}{l}\text { No of } \\
\text { successful } \\
\text { procedures }\end{array}$ & $\begin{array}{l}\text { Success rate } \\
(\%)\end{array}$ & $\begin{array}{l}\text { Total no of } \\
\text { procedures }\end{array}$ & $\begin{array}{l}\text { No of } \\
\text { successful } \\
\text { procedures }\end{array}$ & $\begin{array}{l}\text { Success rate } \\
(\%)\end{array}$ \\
\hline \multicolumn{7}{|l|}{ Restorative procedures } \\
\hline Resin composite & 858 & 769 & 89.6 & 789 & 622 & 78.8 \\
\hline Anterior teeth & 375 & 316 & 84.3 & 364 & 263 & 72.3 \\
\hline Posterior teeth & 483 & 453 & 93.8 & 425 & 359 & 84.5 \\
\hline SSC & 162 & 156 & 96.3 & 183 & 174 & 95.1 \\
\hline \multicolumn{7}{|l|}{ Pulp therapy } \\
\hline IPC & 354 & 340 & 96.0 & 335 & 309 & 92.2 \\
\hline Anterior teeth & 120 & 113 & 94.2 & 122 & 107 & 87.7 \\
\hline Posterior teeth & 234 & 227 & 97.0 & 213 & 202 & 94.8 \\
\hline Pulpectomy & 517 & 488 & 94.4 & 494 & 439 & 88.9 \\
\hline Anterior teeth & 205 & 190 & 92.7 & 190 & 164 & 86.3 \\
\hline Posterior teeth & 312 & 298 & 95.5 & 304 & 275 & 90.5 \\
\hline \multicolumn{7}{|l|}{ Other procedures } \\
\hline Space maintenance & 13 & 10 & 76.9 & 11 & 7 & 63.6 \\
\hline Fissure sealant & 28 & 26 & 92.9 & 28 & 25 & 89.3 \\
\hline
\end{tabular}

IPC, indirect pulp treatment; SSC, stainless steel crown.

OHRQoL significantly improved. However, there was a tendency towards dental caries relapse, and the children's OHRQoL deteriorated over time. The findings of this study have been shared with the participants who expressed the desire to obtain these findings.

Before discussing the findings, the strengths and limitations of the study must be considered. A prospective design, a rare design method in studies observing the clinical outcome of DGA treatment, was used to study clinical outcomes over time, changes in OHRQL scores and caries recurrence, which can be considered a strength of the study. In addition, the validated ECOHIS was used to measure OHRQoL in children. However, a recent study by Thomson $e t a l^{22}$ showed that when applied to children suffering from severe caries, the ECOHIS seems to have some limitations compared with the short-form Parental-Caregiver Perceptions Questionnaire and the FIS. Therefore, the magnitude of the impacts on OHRQoL in our study may partially result from the method used. On the other hand, there are some limitations of this study. First, only $73.6 \%$ and $63.5 \%$ of the patients participated in the 6-month and 12-month follow-up examinations, respectively. Poor compliance with follow-up may indicate poor compliance with the oral health habits that are necessary for the prevention of recurrent caries. ${ }^{1}$ Therefore, samples excluded from the analysis due to absent follow-up recall may have a higher caries recurrence rate, and this may have increased the risk of bias in the relevant findings. Second, the few data points obtained from unscheduled visits by uncalibrated examiners and from the few children who could not cooperate during the examination may have reduced the accuracy of the relevant findings. Third, due to cost constraints, rubber dams are not widely used in paediatric dentistry in our hospital, although they have many benefits and are recommended for various restorative and endodontic procedures. ${ }^{23} 24$ Lack of regular rubber dam use is a significant limitation of this study as it is critical for restorative success. Fourth, according to the findings of this study, there are potential differences between individual dentists. This is considerable in the clinical context and may have an impact on this study.

Regarding the findings, approximately half of the children experienced a procedure failure after their operation. Children receiving DGA treatment may suffer from severe caries and need more treatments, which may increase the risk of failure for each child. Therefore, investigations of the success rate of each treatment procedure and determinations of how to improve the success rate have important clinical significance.

Many studies ${ }^{41525}$ have reported that SSC has a higher success rate in children receiving DGA treatment than is achieved when using other restorative materials. Our findings show that at the 12-month follow-up examination, the success rate of SSCs was significantly higher than that of posterior resin composites, but the difference between the two was not significant at the 6-month follow-up examination. This finding suggests that the long-term effect of SSCs may be better than posterior resin composites. 
Table 3 Caries recurrence at the 6-month and 12-month follow-up examinations

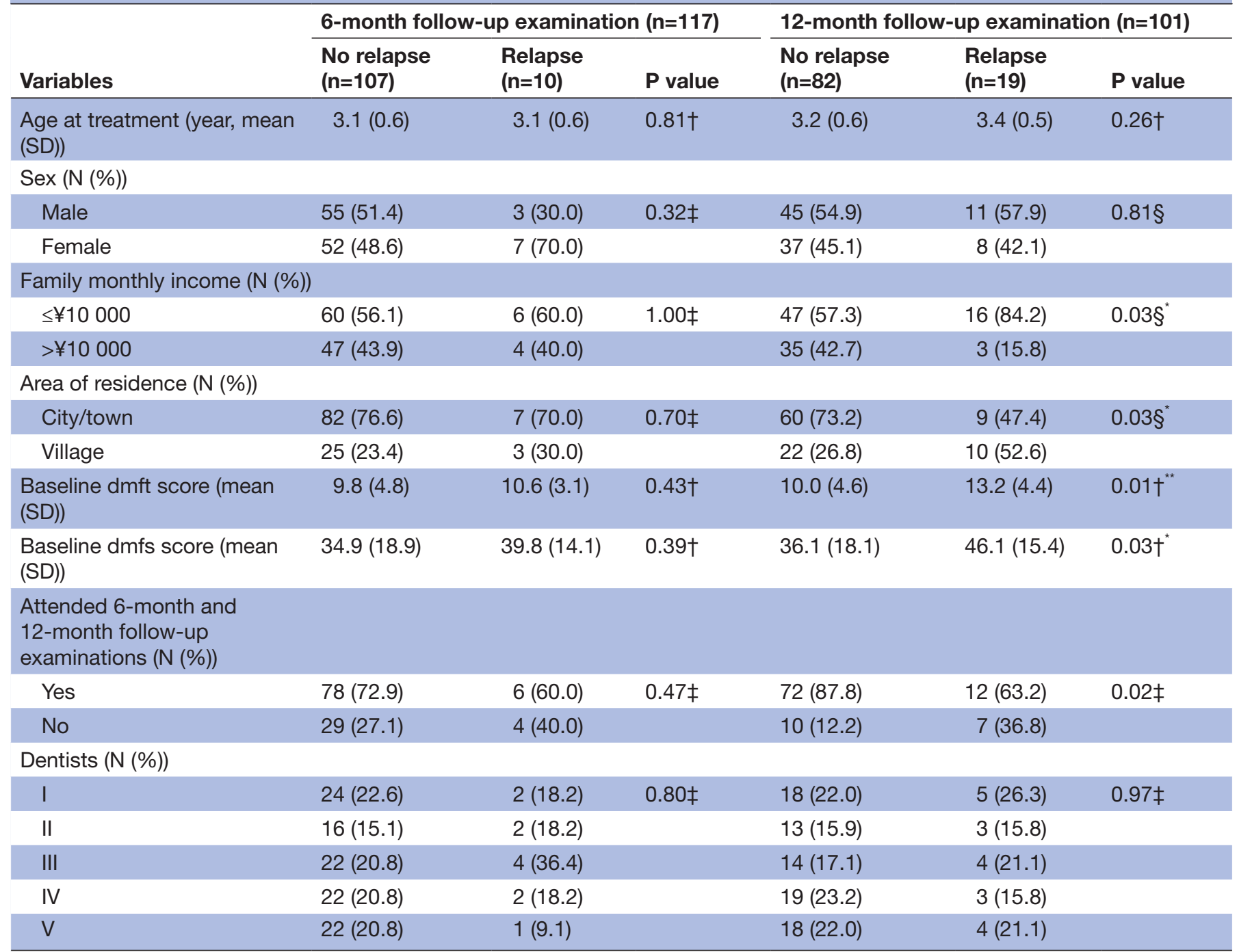

${ }^{*} \mathrm{P}<0.05,{ }^{* *} \mathrm{P}<0.01$.

†Wilcoxon rank test.

†Fisher's exact test.

$\S X^{2}$ test.

dmfs, decayed, missing and filled surface; dmft, decayed, missing and filled teeth.

In this study, the success rates were lower for anterior resin composites than for posterior resin composites. This difference may be because anterior primary teeth have more easily damaged enamel and are under unique forces when chewing. It is, therefore, necessary to carry out the clinical procedures needed, such as the use of advanced bonding agents, ${ }^{26}$ the application of root canal posts to teeth that meet the indication criteria ${ }^{27}$ and the extraction of teeth that are difficult to restore, to improve success rates in the restoration of anterior primary teeth.

According to the American Academy of Pediatric Dentistry, pulpotomy is suitable for the treatment of deep caries without irreversible pulp symptoms. ${ }^{28}$ However, in this study, none of the children received a pulpotomy, consistent with the low prevalence of pulpotomy in China. Pulpotomy usually requires isolation from moisture (eg, rubber dam) to avoid bacterial contamination. Due to the uneven level of medical development, rubber dams have not been widely used in paediatric dentistry in China. In addition, the choice of pulp capping agents for pulpotomy is a problem. Traditional medicines (eg, formocresol and calcium hydroxide) often have unknown effects, ${ }^{29}{ }^{30}$ while advanced medicines (eg, mineral trioxide aggregate) are too expensive for the vast majority of low-income families in China.

Although children with ECC received systematic treatment under GA, a trend towards recurrent caries was still found in this study. The findings show that $8.5 \%$ and $18.8 \%$ of the children required further GA at 6 and 12 months, respectively, because they developed recurrent caries. Unfortunately, these recurrence rates may continue to increase over longer term follow-ups. ${ }^{8} 9$ These findings are not surprising, because the treatment 
Table 4 Mean scores on the entire Early Childhood Oral Health Impact Scale (ECOHIS), child impact section, family impact section (FIS) and each domain at pretreatment and 1, 3, 6 and 12 months post-treatment with effect sizes $(n=151)$

\begin{tabular}{|c|c|c|c|c|c|c|c|c|c|}
\hline \multirow[b]{2}{*}{ ECOHIS domains } & \multirow[b]{2}{*}{$\begin{array}{l}\text { Baseline } \\
\text { Mean (SD) }\end{array}$} & \multicolumn{2}{|c|}{ 1-month follow-up } & \multicolumn{2}{|c|}{ 3-month follow-up } & \multicolumn{2}{|c|}{ 6-month follow-up } & \multicolumn{2}{|c|}{ 12-month follow-up } \\
\hline & & Mean (SD) & $\begin{array}{l}\text { Effect } \\
\text { size }\end{array}$ & Mean (SD) & $\begin{array}{l}\text { Effect } \\
\text { size }\end{array}$ & Mean (SD) & $\begin{array}{l}\text { Effect } \\
\text { size }\end{array}$ & Mean (SD) & $\begin{array}{l}\text { Effect } \\
\text { size }\end{array}$ \\
\hline Child impact section & $5.9(4.7)^{*}$ & $1.7(2.8) \dagger$ & 0.9 & $2.0(3.3) \dagger$ & 0.8 & $2.7(3.5) \dagger$ & 0.7 & 3.8 (4.3)‡ & 0.4 \\
\hline Child symptoms & $1.7(1.0)^{\star}$ & $0.4(0.7) \dagger$ & 1.3 & $0.4(0.8) \dagger$ & 1.3 & $0.5(0.7) \dagger$ & 1.3 & $0.7(0.8) \dagger$ & 1.1 \\
\hline Child function & $2.7(2.6)^{\star}$ & $0.9(1.4) \dagger$ & 0.7 & $1.0(1.6) \dagger$ & 0.7 & $1.4(1.8) \dagger$ & 0.5 & $2.0(2.3)^{\star}$ & 0.3 \\
\hline Child psychology & $0.9(1.3)^{\star}$ & $0.2(0.6) \dagger$ & 0.5 & $0.4(0.8) \dagger \ddagger$ & 0.4 & $0.6(1.0)^{\star} \dagger$ & 0.3 & $0.7(1.1)^{\star} \mp$ & 0.2 \\
\hline $\begin{array}{l}\text { Child self-image } \\
\text { and social } \\
\text { interactions }\end{array}$ & $0.6(1.1)^{*}$ & $0.2(0.5) \dagger$ & 0.4 & $0.3(0.7)^{*}$ & 0.3 & $0.3(0.7)^{\star}$ & 0.3 & $0.5(1.0)^{*}$ & 0.0 \\
\hline FIS & $4.7(3.2)^{\star}$ & $0.9(1.4) \dagger$ & 1.2 & $1.4(1.7) \dagger$ & 1.0 & $1.7(2.1) \dagger$ & 1.0 & $2.3(2.6) \ddagger$ & 0.7 \\
\hline Parent distress & $2.5(2.1)^{\star}$ & $0.5(1.0) \dagger$ & 1.0 & 1.0 (1.1)‡ & 0.7 & $1.0(1.3) \ddagger$ & 0.7 & $1.3(1.5) \ddagger$ & 0.6 \\
\hline Family function & $2.2(1.6)^{\star}$ & $0.4(0.8) \dagger$ & 1.1 & $0.4(0.9) \dagger$ & 1.1 & $0.7(1.0) \dagger \ddagger$ & 0.9 & $1.0(1.3) \ddagger$ & 0.8 \\
\hline Total ECOHIS score & $10.6(6.8)^{*}$ & $2.6(4.0) \dagger$ & 1.2 & $3.4(4.7) \dagger \ddagger$ & 1.1 & $4.3(5.2) \ddagger$ & 0.9 & $6.1(6.4) \S$ & 0.7 \\
\hline
\end{tabular}

Values with the same superscript symbol are not significantly different ( $P>0.05$, Friedman test, post hoc analysis).

approach treats the clinical outcome of caries but does not address the underlying risk factors for ECC..$^{31} 32$

ECC is a multifactorial disease, the development and progression of which are influenced by multiple factors. In this study, the proportions of low-income and rural families and baseline $\mathrm{dmft} / \mathrm{dmfs}$ scores were higher in the relapse group than in the non-relapse group, which is consistent with previous studies. ${ }^{33} 34$ These findings suggest that poor sociodemographic status and baseline dental caries experience are risk factors for ECC. Other risk factors associated with ECC include Streptococcus mutans infection, enamel development defects, inappropriate feeding methods and excessive intake of sugary foods. Therefore, paediatric dentists should not only pay attention to the surgical approach but also provide appropriate oral health guidance and regular postoperative follow-up visits for children treated under GA.

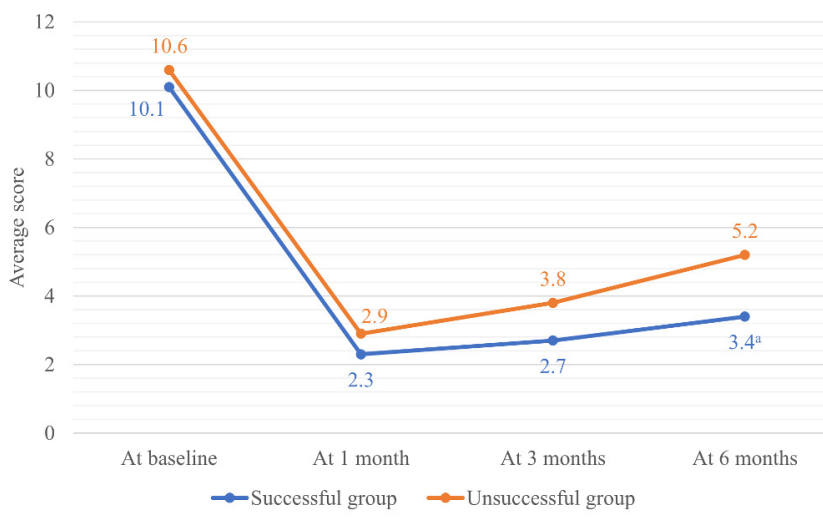

a The score was significantly lower than that for the successful group at the 6-month follow-up ( $\mathrm{P}=0.01$, Wilcoxon rank test).

Figure 2 Changes in Early Childhood Oral Health Impact Scale scores in the successful and unsuccessful groups at the 6-month follow-up examination $(n=117)$.
Oral diseases can result in children experiencing difficulties in food intake, sleep and physical development. In addition, they can also negatively impact the child's family. ${ }^{35}$ Similar to many previous studies, ${ }^{11}$ the findings of this study showed that the total ECOHIS, FIS and CIS scores were significantly lower at 1, 3, 6 and 12 months post-treatment than those obtained pretreatment, suggesting that ECC treatment performed under GA significantly improved OHRQoL in children and that the observed improvements lasted for at least 12 months. Although the postoperative ECOHIS scores were consistently lower than preoperative ECOHIS scores, they increased over time. These findings can be partially attributed to failed procedures and caries recurrence after the treatment. Therefore, to maintain the improvements obtained with treatment, we should carefully evaluate the child's condition before operating, adopt reasonable

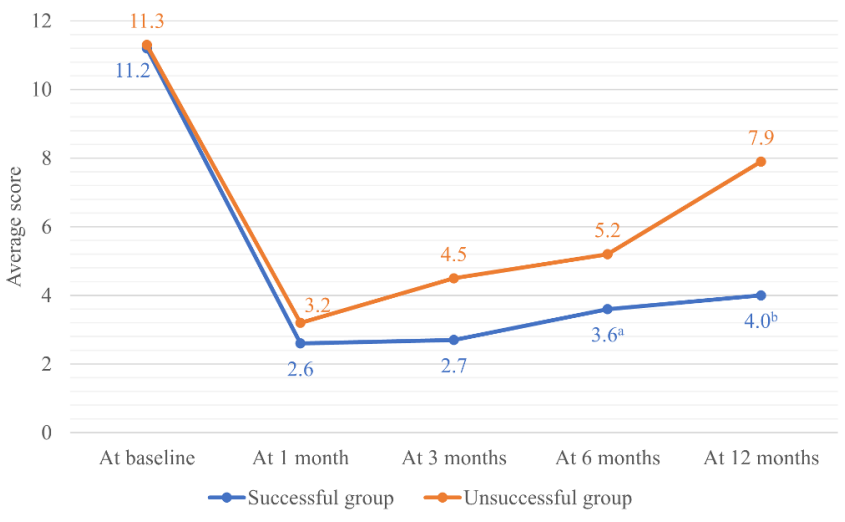

a The score was significantly lower than that of the successful group at the 6-month follow-up $\left(\mathrm{P}=0.04\right.$, Wilcoxon rank test). ${ }^{\mathrm{b}}$ The score was significantly lower than that of the successful group at the 12-month follow-up ( $\mathrm{P}<0.01$, Wilcoxon rank test).

Figure 3 Changes in Early Childhood Oral Health Impact Scale scores in the successful and unsuccessful groups at the 12-month follow-up examination $(n=101)$. 


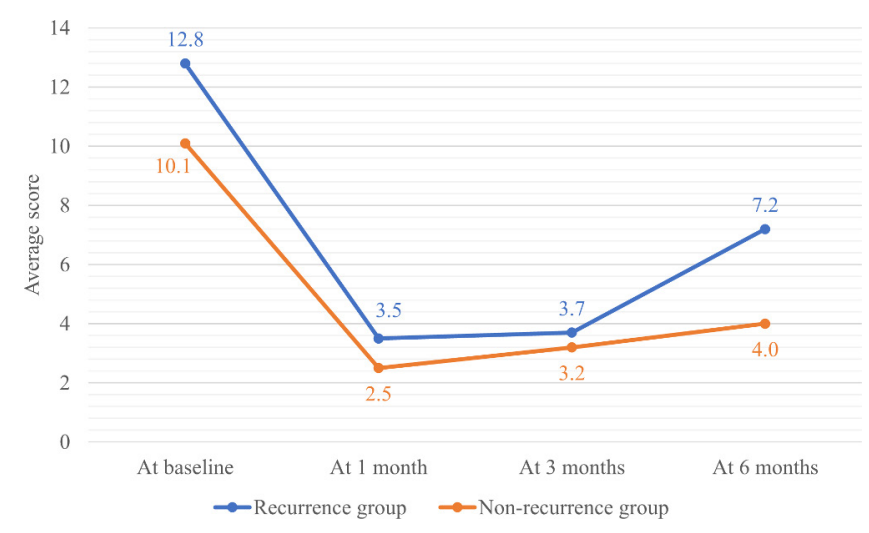

Figure 4 Changes in Early Childhood Oral Health Impact Scale scores in the recurrence and non-recurrence groups at the 6-month follow-up examination $(n=117)$.

and effective treatment strategies, and make an effort to provide appropriate oral health guidance and follow-up strategies to patients.

Our research was conducted at the largest tertiary stomatological hospital in Chongqing, China. The samples included in this study seem to be highly representative of these children because our hospital is the only medical institution providing DGA treatment in Chongqing. Local paediatric dentists and medical decision-makers can benefit from our study. However, the present findings are limited to the city of Chongqing. Future studies with a broad inclusion of patients and hospitals are recommended for the outcome to be representative of the population of Chinese children undergoing GA for dental procedures.

\section{CONCLUSION}

Based on the study findings, we can draw the following conclusions: (1) Procedure failure is commen, and some procedures gradually failed within a few months. Thus, the condition of the children should be carefully evaluated, and reasonable and effective treatment procedures should be selected; (2) We found that there was a trend towards caries recurrence after treatment. Oral

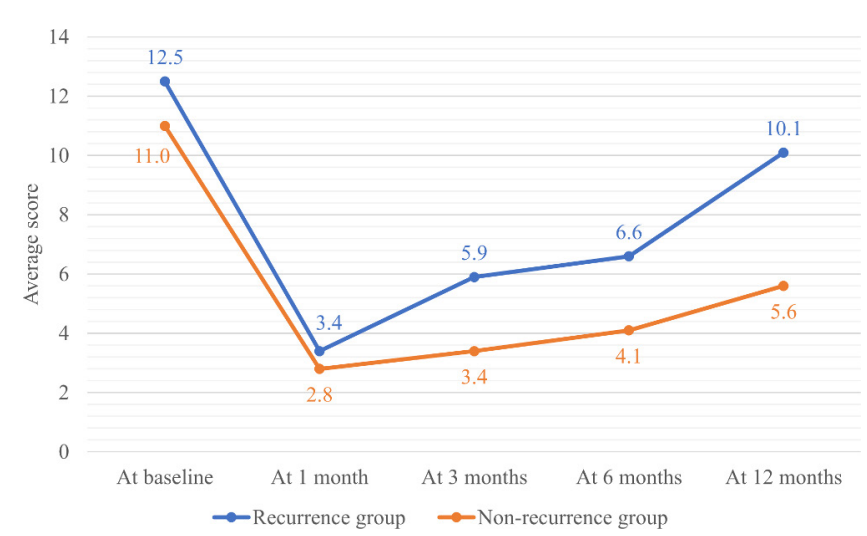

Figure 5 Changes in Early Childhood Oral Health Impact Scale scores in the recurrence and non-recurrence groups at the 12-month follow-up examination $(n=101)$. health guidance and regular postoperative follow-up visits should be emphasised to reduce the occurrence of recurrent caries and (3) ECC that is not treated in a timely manner can have a negative effect on a children's quality of life and on their families. Treating ECC under GA significantly improved the children's OHRQoL, and this improvement lasted for at least 12 months. However, the children's OHRQoL gradually deteriorated throughout the follow-up period.

Contributors JW and HJ designed the study. LS and SH wrote the manuscript. HJ collected the data, and $\mathrm{HJ}$ and $\mathrm{DQ}$ contributed material and analysed the data. All authors reviewed the manuscript.

Funding This study was supported by the Program for Innovation Team Building at Institutions of Higher Education in Chongqing in 2016 (CXTDG201602006) and Chongqing Municipal Key Laboratory of Oral Biomedical Engineering of Higher Education.

Competing interests None declared.

Patient consent for publication Not required.

Ethics approval This study followed all guidelines for ethics in research and abided by the Declaration of Helsinki. Ethical approval was obtained from the Ethics Committee of Stomatological Hospital of Chongqing Medical University (\#2016-011-038).

Provenance and peer review Not commissioned; externally peer reviewed.

Data availability statement All data relevant to the study are included in the article or uploaded as online supplementary information.

Open access This is an open access article distributed in accordance with the Creative Commons Attribution Non Commercial (CC BY-NC 4.0) license, which permits others to distribute, remix, adapt, build upon this work non-commercially, and license their derivative works on different terms, provided the original work is properly cited, appropriate credit is given, any changes made indicated, and the use is non-commercial. See: http://creativecommons.org/licenses/by-nc/4.0/.

\section{REFERENCES}

1. Foster T, Perinpanayagam $\mathrm{H}$, Pfaffenbach $\mathrm{A}$, et al. Recurrence of early childhood caries after comprehensive treatment with general anesthesia and follow-up. J Dent Child 2006;73:25-30.

2. Cantekin K, Yildirim MD, Cantekin I. Assessing change in quality of life and dental anxiety in young children following dental rehabilitation under general anesthesia. Pediatr Dent 2014;36:12E-17.

3. National Health and Family Planning Commission of China. The fourth national oral health epidemiological survey, 2017Online Information Available at. Available: www.gov.cn/xinwen/2017-09/19/ content_5226124.htm\#1 [Accessed May 2018].

4. Eshghi $\bar{A}$, Samani MJ, Najafi NF, et al. Evaluation of efficacy of restorative dental treatment provided under general anesthesia at hospitalized pediatric dental patients of Isfahan. Dent Res $J$ 2012;9:478-82.

5. Ramazani N. Different aspects of general anesthesia in pediatric dentistry: a review. Iran J Pediatr 2016;26:e2613.

6. Tate AR, MW N, Needleman HL, et al. Failure rates of restorative procedures following dental rehabilitation under general anesthesia. Pediatr Dent 2002;24:69-71.

7. Amin MS, Bedard D, Gamble J. Early childhood caries: recurrence after comprehensive dental treatment under general anaesthesia. Eur Arch Paediatr Dent 2010;11:269-73.

8. Amin M, Nouri R, ElSalhy M, et al. Caries recurrence after treatment under general anaesthesia for early childhood caries: a retrospective cohort study. Eur Arch Paediatr Dent 2015;16:325-31.

9. Jabarifar SE, Eshghi AR, Shabanian M, et al. Changes in children's oral health related quality of life following dental treatment under general anesthesia. Dent Res J 2009;6:13-16.

10. El-Meligy O, Maashi M, Al-Mushayt A, et al. The effect of full-mouth rehabilitation on oral health-related quality of life for children with special health care needs. Journal of Clinical Pediatric Dentistry 2016;40:53-61.

11. Park JS, Anthonappa RP, Yawary R, et al. Oral health-related quality of life changes in children following dental treatment under general anaesthesia: a meta-analysis. Clin Oral Investig 2018;22:2809-18. 
12. Thomson W. Public health aspects of paediatric dental treatment under general anaesthetic. Dentistry Journal 2016;4.

13. World Health Organization. Oral health surveys - basic methods. 5th edn. Geneva: World Health Organization, 2014

14. Al-Eheideb A, Herman N. Outcomes of dental procedures performed on children under general anesthesia. Journal of Clinical Pediatric Dentistry 2004;27:181-3.

15. Mallineni SK, Yiu CKY. A retrospective review of outcomes of dental treatment performed for special needs patients under general anaesthesia: 2-year follow-up. ScientificWorldJournal 2014;2014:1-6.

16. Lee GHM, Mcgrath C, Yiu CKY, et al. Translation and validation of a Chinese language version of the early childhood oral health impact scale (ECOHIS). Int J Paediatr Dent 2009;19:399-405.

17. Lee GHM, McGrath C, Yiu CKY, et al. Sensitivity and responsiveness of the Chinese ECOHIS to dental treatment under general anaesthesia. Community Dent Oral Epidemiol 2011;39:372-7.

18. Pahel BT, Rozier RG, Slade GD. Parental perceptions of children's oral health: the early childhood oral health impact scale (ECOHIS). Health Qual Life Outcomes 2007;5:6.

19. Jankauskiené B, Virtanen JI, Narbutaité J. Follow-up of children's oral health-related quality of life after dental general anaesthesia treatment. Acta Odontol Scand 2017;75:255-61.

20. Jankauskiené B, Virtanen JI, Kubilius $\mathrm{R}$, et al. Oral health-related quality of life after dental general anaesthesia treatment among children: a follow-up study. BMC Oral Health 2014;14:81.

21. Wong S, Anthonappa RP, Ekambaram M, et al. Quality of life changes in children following emergency dental extractions under general anaesthesia. Int J Paediatr Dent 2017;27:80-6.

22. Thomson WM, Foster Page LA, Malden PE, et al. Comparison of the ECOHIS and short-form P-CPQ and FIS scales. Health Qual Life Outcomes 2014:12:36.

23. Soldani F, Foley J. An assessment of rubber dam usage amongst specialists in paediatric dentistry practising within the UK. Int $J$ Paediatr Dent 2007:17:50-6.

24. Varughese RE, Andrews P, Sigal MJ, et al. An assessment of direct restorative material use in posterior teeth by American and
Canadian pediatric dentists: II. rubber dam isolationd. Pediatr Dent 2016;38:497-501.

25. Amin M, Nouri MR, Hulland S, et al. Success rate of treatments provided for early childhood caries under general anesthesia: a retrospective cohort study. Pediatr Dent 2016;38:317-24.

26. Yaseen SM, Subba Reddy VV. Comparative evaluation of shear bond strength of two self-etching adhesives (sixth and seventh generation) on dentin of primary and permanent teeth: An in vitro study. J Indian Soc Pedod Prev Dent 2009;27:33-8.

27. Sawant A, Chunawalla $Y$, Morawala A, et al. Evaluation of novel glass fiber-reinforced composite technique for primary anterior teeth with deep carious lesions: a 12-month clinical study. Int J Clin Pediatr Dent 2017;10:126-30.

28. American Academy on pediatric dentistry. guideline on pulp therapy for primary and young permanent teeth. Pediatr Dent 2014;36:242-50.

29. Airen P, Shigli A, Airen B. Comparative Evaluation of Formocresol and Mineral Trioxide Aggregate in Pulpotomized Primary Molars - 2 Year Follow Up. Journal of Clinical Pediatric Dentistry 2012;37:143-7.

30. Lin $\mathrm{P}-\mathrm{Y}$, Chen $\mathrm{H}-\mathrm{S}$, Wang $\mathrm{Y}-\mathrm{H}$, et al. Primary molar pulpotomy: a systematic review and network meta-analysis. J Dent 2014;42:1060-77.

31. Schroth RJ, Halchuk S, Star L. Prevalence and risk factors of caregiver reported severe early childhood caries in Manitoba first nations children: results from the Rhs phase 2 (2008-2010). Int J Circumpolar Health 2013;72:21167 https://doi.org/

32. Schroth RJ, Quiñonez C, Shwart L, et al. Treating early childhood caries under general anesthesia: a national review of Canadian data. J Can Dent Assoc 2016:82.

33. Mejàre I, Axelsson $\mathrm{S}$, Dahlén $\mathrm{G}$, et al. Caries risk assessment. A systematic review. Acta Odontol Scand 2014;72:81-91.

34. Reisine S, Litt M, Tinanoff N. A biopsychosocial model to predict caries in preschool children. Pediatr Dent 1994;16:413-8.

35. Ridell K, Borgström M, Lager $\mathrm{E}$, et al. Oral health-related qualityof-life in Swedish children before and after dental treatment under general anesthesia. Acta Odontol Scand 2015;73:1-7. 